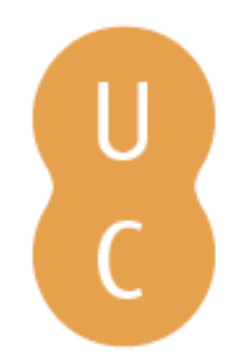

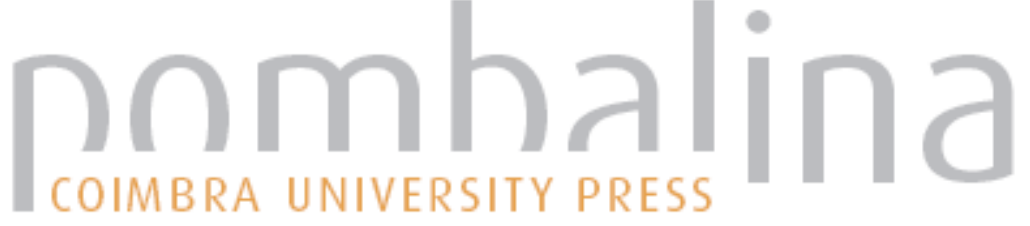

\section{Demotikos e demokratikos na paideia de Plutarco}

Autor(es): $\quad$ Ferreira, José Ribeiro

Publicado por: Centro de Estudos Clássicos e Humanísticos

URL

persistente:

URI:http://hdl.handle.net/10316.2/32128

DOI:

DOI:http://dx.doi.org/10.14195/978-989-721-062-4_4

Accessed : $\quad$ 26-Apr-2023 12:08:32

A navegação consulta e descarregamento dos títulos inseridos nas Bibliotecas Digitais UC Digitalis, UC Pombalina e UC Impactum, pressupõem a aceitação plena e sem reservas dos Termos e Condições de Uso destas Bibliotecas Digitais, disponíveis em https://digitalis.uc.pt/pt-pt/termos.

Conforme exposto nos referidos Termos e Condições de Uso, o descarregamento de títulos de acesso restrito requer uma licença válida de autorização devendo o utilizador aceder ao(s) documento(s) a partir de um endereço de IP da instituição detentora da supramencionada licença.

Ao utilizador é apenas permitido o descarregamento para uso pessoal, pelo que o emprego do(s) título(s) descarregado(s) para outro fim, designadamente comercial, carece de autorização do respetivo autor ou editor da obra.

Na medida em que todas as obras da UC Digitalis se encontram protegidas pelo Código do Direito de Autor e Direitos Conexos e demais legislação aplicável, toda a cópia, parcial ou total, deste documento, nos casos em que é legalmente admitida, deverá conter ou fazer-se acompanhar por este aviso. 
Colecção Autores Gregos e Latinos Série Ensaios

\section{Carmen Soares \\ José Ribeiro Ferreira Maria do Céu Fialho}

Ética e Paideia em Plutarco 


\section{Demotikos e Demokratikos na Paideia de Plutarco}

José Ribeiro Ferreira

Este trabalho, baseado sobretudo nas Vidas Paralelas, pretende mostrar que o herói de Plutarco, embora homem da pólis e seu servidor, encarna também todos os seus valores: humano, polido, amável, cortês, culto, benevolente, romano ou grego - uma noção que está próxima do ideal do homem da cidade e que corresponde ao próprio ideal de civilização e que não está longe afinal de uma visão da doçura como virtude democrática. Por outro lado, procurar-se-á perceber por que razão Plutarco dá ao homem de modos simples e afáveis o apelido demotikos ("amigo do povo") ou "democrático", associando a palavra a philanthropia. Por exemplo, para designar a simplicidade e afabilidade de Agesilau usa os termos demotikos e philanthropos (Ages. 1.5). Na Vida de Luculo (44.5), ao comparar as refeiçóes de Luculo com as de Címon, contrapóe a do primeiro, faustosa como a de um sátrapa, à do segundo, democrática (demokratike) e generosa (philanthropos). Por outro lado, para designar actos humanos e benevolentes, aparece a associação dos adjectivos "helénico", doce (praos), humano (philanthropos).

Exalta Plutarco as épocas áureas da Grécia e de Roma, e povoa as Vidas paralelas de heróis, cujas virtudes convidam à imitação: frugalidade, simplicidade, 
honestidade, diligência, temperança, inteligência, autodomínio, coragem, integridade, justiça, amor à pátria e amor à liberdade. ${ }^{1}$

Este conjunto de qualidades — ora de índole militar, ora de índole mais intelectual — segundo estudo de C. Panagopoulos, ${ }^{2}$ pode agrupar-se nas seguintes virtudes principais: engenia, riqueza, amor da glória, bons costumes, espírito de família, doçura, coragem, justiça, inteligência, excelência; ou ser reduzido, na opinião de Françoise Frazier (1996: 173-273), a quatro virtudes principais, tanto para as Vidas como para os Moralia: coragem (andreia), inteligência (phronesis), justiça (dikaiosyne) e autodomínio (sophrosyne). Encaminha-nos para esta última listagem o De audiendis poetis - um tratado dedicado à educação, à paideia - onde Plutarco recomenda que se ensine aos jovens a andreia, a sophrosyne, a dikaiosyne (30D) e a phronesis que é, na opinião de Homero, a «qualidade mais adequada a um deus e a um rei» (32A).

Plutarco, ao enumerar estas virtudes, pensa num ideal grego, mas, homem integrado no império romano, tem consciência de que Hélade e Roma formavam um todo cultural. Se defende a civilização que, por essência, é grega - e que transparece em muitos dos seus heróis,

${ }^{1}$ Neste trabalho baseio-me sobretudo nas Vidas Paralelas, por interessarem mais as virtudes em acção e por os heróis aí biografados constituírem paradigmas que sempre exerceram forte fascínio ao longo dos tempos. Não esquecerei evidentemente os Moralia, e para eles remeterei a cada passo.

2 Estudo realizado a partir das inscriçóes citadas nos Tratados morais 1977: 197-235. 
através de virtudes por eles praticadas -, esses valores impregnaram profundamente a cultura romana, até construírem uma cultura homogénea.

É conhecimento adquirido que Roma, apesar de conquistadora, recebeu a cultura e muitos dos valores da Grécia, como refere Horácio, no famoso passo das Epistolas (Epist. 2.1. 156-157) :

Graecia capta ferum victorem cepit et artes Intulit agresti Latio.

Plutarco sublinha essa atracçáo da cultura grega sobre os Romanos. Dou, como exemplo, o seguinte e significativo passo da Vida de Marcelo, onde, na apreciação das qualidades do estadista, a moderação e a humanidade se encontram ao mesmo nível do domínio e interesse pela cultura e língua gregas (1.3):

Era moderado (sophron), humano (philanthropos) e amante da cultura e literatura gregas, a ponto de honrar e admirar aqueles que as cultivavam com êxito; mas ele próprio, devido às suas ocupaçóes, náo as podia exercer e aprender quanto era seu desejo.

Para Plutarco, o império romano é cadinho e garante da perenidade dessa civilização greco-romana que se foi formando aos poucos e que ele próprio cimenta definitivamente, ao aproximar por sistema a biografia de um romano da de um grego, exaltando as qualidades e virtudes de um e de outro e denunciando os seus defeitos. 
E um dos traços mais salientes e mais exaltados dos heróis biografados por Plutarco reside na sua doçura e humanidade, a característica doçura grega, «essenciellement une vertu de sociabilité, de tolérance et d'indulgence», como a define J. de Romilly (1979: 328). Depois de uma pormenorizada análise dessa qualidade grega - que se aproxima da clementia romana, mas que com ela se náo confunde, por ser mais ampla -, a helenista francesa considera ser nos fins da literatura grega, com Plutarco, que encontramos o apogeu dessa noção de doçura: todas as tradiçôes a ela relativas, todas as palavras para a designar, todas as formas de a conceber vêm de certo modo confluir na obra do filósofo de Queroneia (1979: 278).

Qualidade que se pode educar, a doçura intervém praticamente em todos os aspectos da vida do herói: aparência, comportamento, modo de vida ou acçôes. E assim presente em todo o lado, tudo comanda, aparecendo como ideal de vida essencialmente grego, traduzido no próprio vocabulário: praotes "mansidão", "doçura"; epieikeia (ou o adjecttivo epieikes) que se aproxima de "igualdade" ou indulgência; philanthropia ou philanthropos "humanidade". ${ }^{3}$ As duas primeiras, virtudes de carácter mais pessoal, impregnam o comportamento e manifestam contenção física. ${ }^{4}$ A philanthropia,

${ }^{3}$ Os termos praotes (contabilizando as palavras da família) e epieikeia (ou o adjecttivo epieikeios) aparecem mais de 100 vezes cada um; philanthropia e philanthropos são utilizados cerca de 50 vezes.

${ }^{4}$ Quanto à praotes - que é antes de mais uma resistência interior à cólera e à violência, aos prazeres (cf.Brut. 1.3) — o autor 
pelo contrário, traduz uma postura ou uma actuação que se volta para fora, para o convívio social, o contacto com os outros.

Nas Vidas paralelas, o herói não é um homem só, mas surge sempre como responsável por outros, um chefe que deve velar pela salvação do exército e do estado, cuja prudência protege e cuja resolução galvaniza os outros. Talvez por isso a virtude suprema nas Vidas seja a dikaiosyne, que se aproxima da philanthropia, mas também do que exprimem adjectivos como demotikos e hellenikos (e suas substantivaçôes) - ou seja cultura, afabilidade, humanidade, benevolência, sociabilidade.

Os termos philanthropia ou philanthropos, e outros que com estes se relacionam, - utilizados cerca de três centenas de vezes na obra de Plutarco ${ }^{5}$ - exprimem uma qualidade que, virada para o exterior, se dilata até abraçar a humanidade inteira. Com ligação indissociável à civilização e ao helenismo e eminentemente sociável, traduz um modo de viver agradável e educado com os amigos, tendendo no campo das relaçôes humanas para a philia, ${ }^{6}$ e, segundo as circunstâncias, pode tomar cores de afabilidade, de cortesia, de liberalidade, de gentileza, de bondade ou de clemência. Assim Fó-

mostra que ela cobre o domínio físico e moral, reveste aspectos intelectuais e se associa à legalidade.

5 Mais especificamente, segundo consulta informática ao T.L.G., temos 293 ocorrências: 54 de philanthropia, 235 de philanthropos ( 45 dos quais na forma adverbial) e 4 de philanthropeuma

${ }^{6}$ Jr. H. Martin 1961: 164-175. Na p. 174, considera que a philanthropia é a virtude por excelência do homem civilizado. 
cion, embora rude, inflexível e inexorável quando se tratava de medidas propostas para o bem da pátria, era no resto «benevolente para todos, acessível e humano».7 Por outro lado, segundo um passo dos Moralia «quem é sociável, humano, patriota, cuidadoso do bem público e verdadeiramente político ${ }^{8}$ dedica o seu tempo às tarefas da pólis.

Plutarco é sensível a tudo o que é solidariedade humana. Segundo J. de Romilly (1979: 276), é o primeiro a usar o verbo synanthopeo "ser homem em conjunto”. Um passo dos Preceitos Políticos (Moralia 823B) informa que Hérmon nunca foi importuno com os serviçais, nem sobressaía pelo luxo e sumptuosidade, mas procurava ser igual aos outros - no modo de vestir, no género de vida, na educação dos filhos, na toalete da mulher - para ser homem igual aos outros ou em conjunto com os outros (synanthropein). Por outro lado, Plutarco, no tratado Acerca do amor fraterno (Moralia 479C), critica o carácter solitário (aphilanthropos): defende a necessidade de o homem procurar a amizade e a companhia das pessoas, viver em sociedade, já que, sem contrariar a natureza, ninguém pode viver sem amigos, sem relaçôes de uns com os outros, solitário. ${ }^{9}$

Falhar no que respeita à humanidade é defeito que o adjectivo apanthropos estigmatiza. ${ }^{10}$ Assim Plu-

${ }^{7}$ Phocion 10.7: eumene ... kai koinon kai philanthropon.

8 796E.

9 Cf. ainda Mor. 1098D onde aparece a mesma censura ao aphilanthropos.

10 Encontramos o adjectivo em outros autores. E. g. Dionísio de Halicarnasso 6. 81; Apiano 7. 5. 28. 
tarco opóe a apanthropia à philanthropia: um passo da Vida de Dion (7.5) refere que este, enfraquecendo a tirania, fê-la parecer humana (philanthropos), retirando-lhe o que tinha de excessivamente inumano (lian apanthropon). A moderação, simplicidade e humanidade de Díon aparece sublinhada em outros passos, Apenas mais um exemplo: feito o relato da tomada de Siracusa e apontados a grandeza, o poder e a glória de Díon, Plutarco refere que este «se mostrava tão moderado no vestuário, nos serviçais, na mesa, como se vivesse na Academia com Platão e não no meio de chefes militares e de mercenários» (Dion 52.3).

Com ligaçôes estreitas com outra característica saliente dos heróis de Plutarco, a charis que exprime o tratamento agradável, ameno, recíproco entre o que é beneficiado e o que beneficia, ${ }^{11}$ a philanthropia intervém praticamente em tudo o que interessa no carácter do herói. Trata-se de uma tendência pessoal que se pode educar. Assim o sugere um passo do Banquete dos Sete Sábios (148D), em que a jovem Cleobulina-Eumétis, sagaz, hábil, inteligente e generosa (philanthropos), conseguia tornar o seu pai, Cleobulo, «mais doce para os seus súbditos e mais amigo do povo" (praoteros e demotikoteros).

O herói de Plutarco é assim um homem sociável, da pólis como sistema de vida e entidade formadora e educadora; não apenas o servidor dessa cidade, mas também a encarnação de todos os seus valores: humano,

11 Vide C. Meier 1987: 37. 
polido, amável, cortês, culto, benevolente, romano ou grego. Trata-se de uma concepção que está próxima do ideal do homem da cidade e que, segundo Frazier 1996: 274, corresponde ao próprio ideal de civilização. Não estamos longe afinal de uma visão da doçura como virtude democrática. Parece-me por isso ter razão J. de Romilly 1979: 279, quando sublinha que à tradição platónica de que o sábio suporta a adversidade praos, "com doçura" ou "com serenidade", Plutarco alia uma tradição diferente, expressa nos oradores áticos, que via na doçura uma virtude democrática. Não são raras as vezes em que Plutarco dá ao homem de modos simples e afáveis o epíteto de demotikos ('amigo do povo') ou demokratikos, associando estas palavras aos termos metrios, praotes, philanthropia e outras das mesmas famílias. Por exemplo, na Vida de Sólon refere que o Estadista ateniense, que pertencia a famílias aristocráticas, era um "homem do povo" (16.2: demotikos), que preferia a vida e a morte de um homem do povo (27.6: demotikos) e de um simples particular; observa ainda que a divindade, ao conceder aos Gregos serem em tudo moderados (metrios), parece ter feito nascer uma sabedoria prudente e demotike, nem real, nem brilhante (27.7-8).

Para sublinhar a simplicidade e afabilidade de Agesilau associa a palavra demotikos a philanthropia, referindo que o rei tinha um carácter "demótico e filantropo» — ou seja «simples e humano» —, e que à sua qualidade de chefe e de rei unia a simplicidade e a afabilidade da educação (to demotikon kai philanthropon). ${ }^{12}$ Por outro lado, em

12 Ages. 1.5. 
contraste com os outros reis que ostentavam riqueza e manifestavam desdém para com os que se lhe dirigiam, Cleómenes, pelo contrário, não ostenta qualquer fausto real, mas vinha ao encontro deles com grande simplicidade, estendendo-lhes a mão, conversando com eles e escutando as suas solicitaçóes, com aspecto alegre e afável (hilaros e philanthropos), a ponto de todos "ficarem agradados com os seus modos democráticos». ${ }^{13}$ Efeito oposto provoca Rómulo que não soube evitar o inebriamento do poder e do sucesso; pelo contrário, «seduzido pela prosperidade e cheio de orgulho insuportável, perdeu o aspecto simples (demotikos) e passou a pender para a monarquia que, em primeiro lugar, importunava e feria devido à ostentação de que se rodeava». ${ }^{14} \mathrm{Na}$ Vida de Luculo (44.5), ao comparar as refeiçóes de Luculo com as de Címon, Plutarco contrapóe a mesa do primeiro, faustosa como a de um sátrapa, à do segundo, democrática (demokratike) e generosa (philanthropos).

E assim os passos opóem as maneiras simples, afáveis, humanas ou demóticas à ostentação e aparato da monarquia ou riqueza. ${ }^{15}$ Outras vezes a oposição pode verificar-se entre demótico e moderado (metrios), por um lado, e o rigor e a dureza, por outro, como acontece num passo da Vida de Publícola 12. 1: o dirigente mostra-se demótico e moderado (metrios), como nomoteta, mas rigoroso e intransigente, no caso de crimes desmedidos.

${ }^{13}$ Cleom. 13.3.

${ }^{14}$ Rómulo 26.1.

${ }^{15} \mathrm{Cf}$. ainda Publicola $11.4 \mathrm{em}$ que o termo demotikos parece ter um sentido próximo de 'republicano' ou, talvez com mais propriedade, que vive num sistema náo autocrático. 
Mais surpreendente ainda é a admissão na obra de Plutarco de outra equivalência, também frequente nos oradores áticos, de uma doçura ateniense ou melhor grega. Traduz-se pela associação do adjectivo 'helénico' a praos e philanthropos. É o que se verifica na Vida de Filipomen. Aí, em 8.1, afirma que Arato fez crescer a confederação aqueia «em dignidade e em poder», unindo as póleis e praticando uma política «helénica e generosa». ${ }^{16}$

Por outro lado, para designar actos humanos e benevolentes, aparece a associação dos adjectivos "helénico", doce (praos), humano (philanthropos) - e advérbios correspondentes. Um passo da Vida de Marcelo fala dos procedimentos helénicos e doces dos Romanos para com os deuses e do seu constrangimento, ao verem-se obrigados, desencadeada a guerra, a enterrarem dois Gregos e dois Gauleses, por indicação dos oráculos sibilinos (3. 6):

Eles que não praticavam qualquer acto bárbaro ou estranho, mas que mostravam nas suas opiniōes, sentimentos helénicos e doces para com os deuses, viram-se constrangidos, declarada a guerra, a enterrar dois Gregos, um homem e uma mulher, e igualmente dois Gauleses.

Portanto, ter ou sentir disposições helénicas ou doces no culto aos deuses opóe-se ao procedimento dos bárbaros e aos actos e sacrifícios desumanos e cruéis.

É mais explícito ainda um passo da Vida de Lisandro, em que, após citar o decreto dos Tebanos a conceder

${ }^{16}$ Filipoimen 8.1: helleniken kai philanthropon politeian. 
asilo e apoio aos Atenienses que fugiam ao regime dos Trinta Tiranos (404-403 a.C.) e contra ele lutavam (27.6), Plutarco escreve:

E não se limitaram a votar medidas tão helénicas e tão humanas; apresentaram acçóes consentâneas com os decretos... ${ }^{17}$

É curioso e significativo o uso de hellenikos neste passo, porque são Gregos que actuam. O da Vida de Marcelo ainda poderia compreender-se que se diga "à maneira dos Helenos", porque estão em causa Romanos, mas no passo da Vida de Lisandro só pode ter o sentido de "simples, civilizado".

Em contraste com estas ocorrências de demotikos e hellenikos aplicados à pessoa moderada, simples e humana, o homem rude e violento é considerado oligárquico. Na obra de Plutarco são dezoito as ocorrências do termo oligarchikos, algumas das quais com o sentido de violento, grosseiro. Alguns exemplos: Coriolano, que, apesar da sua temperança (enkrateia), justiça e coragem, é rude e violento nas suas relaçôes com os concidadãos, aparece classificado de "insuportável, grosseiro (acharis) e orgulhoso ou "oligárquico" (1.3-4). Na comparação da sua conduta política de Coriolano com a de Alcibíades, Plutarco volta a utilizar quase as mesmas palavras, ao classificar a sua actuação de desagradável, orgulhosa

${ }^{17}$ Lys. 27.7. Cf. também Marc. 1.3 já citado acima, onde aparece sentido idêntico. 
e oligárquica ${ }^{18}$ e ao sublinhar que provocava o ódio do povo. Por outro lado somos informados de que Nícias, com um comportamento pouco humano e não democrático, mostrava uma atitude insociável e oligárquica, que parecia estranha.

Ou seja, o herói que é amável e humano recebe os epítetos de democrático e helénico, enquanto o que é rude e grosseiro é "oligárquico". Em contrapartida, quem é moderado, simples, afável, humano aparece designado por demótico, democrático, helénico. Os longos, mas elucidativos, caminhos das palavras.

Por outro lado, em associação com os termos philanthropia, demotikos e hellenikos, acima analisados, colocado lado a lado com eles e a designar a pessoa dotada - ou imbuída graças à educação - com as qualidades e virtudes que tais termos traduzem aparece o particípio perfeito médio-passivo pepaideumenos que significa 'intruído', 'bem formado', 'educado'. São vinte as ocorrências e todas elas sublinham o aspecto positivo das qualidades que se obtiveram através da educação. Pode ter o sentido de pessoa competente, hábil, preparado (cf. Lyc. 13.2 e 19.1), de "homem conhecedor das letras». ${ }^{19} \mathrm{~A}$ propósito de Luculo, Plutarco refere que o general preferia os louvores que derivavam da justiça e da humanidade (apo dikaiosynes kai philanthropias) aos que advinham dos sucessos militares, já que estes adquiriam-se apenas numa pequena parte graças ao exército e na sua maioria por efeito da tyche ou sorte, enquanto a justiça

18 Cor. 40.3.

${ }^{19}$ Dio 11.4: andra kai pepaideumenon peri logous. 
e a humanidade são fruto de um espírito doce e culto. ${ }^{20}$ Ao comparar as juventudes de Címon e de Luculo ( $L u c$. 44.4), informa que a do primeiro foi repreensível e desregrada, ao passo que a do segundo foi disciplinada e sensata (pepaideumene kai sophron).

$\mathrm{Na}$ Vida de Alexandre o particípio aparece associado à educação helénica. $\mathrm{O}$ jovem Estadista, ao conquistar Issos, por considerar mais digno de um rei vencer-se a si mesmo do que triunfar dos seus inimigos, não tocou nas mulheres, com excepção da viúva de Mémnon, Barsine, por se tratar de uma mulher que tinha uma educação grega (paideian Helleniken) e era de maneiras doces (ton tropon epieikes). ${ }^{21}$

Ocorrências com sentido idêntico poderemos encontar nos Moralia. Dou apenas um exemplo tirado da Consolação de Apolónio 102F-103A, em que se acentua que é próprio de homens bem formados e sensatos ( $p e-$ paideumenon kai sophronon andron) continuarem eles próprios diante da felicidade e guardar perante a desgraça uma atitude digna. ${ }^{22}$

Deste modo as Vidas fazem brilhar a paideia antiga - que também não está ausente das propostas dos Moralia -, propondo como ideal o de um herói pepaideumenos "instruído", culto, bem formado; são elas próprias obras primas de paideia destinada a aumentar a paideia dos leitores: os heróis aí biografados tornaram-se paradigmas e foram imitados ao longo dos tempos e

${ }^{20}$ Luc. 29.6.

${ }^{21}$ Alex. 21.9.

${ }^{22}$ Cf. ainda Moralia 117E. 
acabaram por ajudar a construir os valores da Europa. O pepaideumenos é o que, pela educação e formação, adquiriu doçura, moderação, sensatez, humanidade, simplicidade, ou seja se tornou praos, metrios, sophron, philanthropos, demotikos. 